Abeledo Carrillo, Lara.

Estudiante del "Programa de doutoramento en Investigación e creación en Arte contemporánea", Universidade de Vigo.

\title{
Arte y fotografía doméstica en la era de internet. Algunos casos significativos.
}

\author{
TIPO DE TRABAJO
}

Comunicación.

PALABRAS CLAVE

Fotografía, fotografía doméstica, arte, internet, diarios visuales.

KEY WORDS

Photography, domestic photography, art, internet, visual diary.

\section{RESUMEN}

La fotografía desde su nacimiento supuso un cambio radical en la cultura visual. Pero no es hasta 1888 con el lanzamiento de la primera cámara Kodak, que se convierte en una técnica accesible para todos. El famoso eslogan "usted apriete el botón, nosotros hacemos el resto" estaba asociado a una cámara manejable por cualquier usuario. Este hecho propició el surgimiento de la fotografía doméstica y familiar y su extensión a amplias capas sociales.

Fotografiar la vida cotidiana es, desde entonces, una práctica habitual que se ha acrecentado por la irrupción de la fotografía digital e internet. Son numerosos los artistas que, haciendo relectura del extenso imaginario creado por decenios de práctica de este tipo de fotografía, convierten sus vivencias domésticas en el motivo de su obra.

Si el aspecto autobiográfico pudiera ser un rasgo muy común a numerosos trabajos artísticos, la cotidianidad como pretexto creativo se materializa a través de la técnica fotográfica y con la evolución del fenómeno del álbum familiar. Así, durante los años 80 y 90 surgen artistas que captan su propia realidad como proyecto artístico. Artistas como Richard Billingham o Nan Goldin, que parecen reflejar una espontaneidad absoluta, recurriendo a una fotografía cruda, con flash y sin artificios; otros, como Sally Mann, que recurren a una estética más cuidada y preciosista. Estos trabajos previos a la llegada de la era digital, son la antesala de un tipo de artistas jóvenes, cuyo trabajo no puede entenderse sin ese océano de imagénes que supone internet, las redes sociales y su funcionamiento como ventanas de lo cotidiano. Olivia Bee, Maya Kapouski o Alejandra Vacuii, realizan diarios visuales que cabalgan entre lo analógico y lo digital, lo doméstico y lo artístico, conformando propuestas vinculadas al mismo mundo visual generado y desarrollado por prácticas fotográficas domésticas y privadas, ahora sobredimensionado por internet.

\section{ABSTRACT (En inglés)}

Since the inception of Photography, it presented radical changes in visual culture. But it was not until 1888 with the release of the first Kodak camera, which turns into an accessible art for everyone. The famous slogan "You press the button, we do the rest" was associated with a manageable camera by any user. This led to the emergence of domestic and family photography and its extension to broad social layers.

Photographing everyday life is, then, a practice that has been heightened by the emergence of digital photography and the Internet. Numerous artists, making extensive reinterpretation of imagery created by decades of practice for this type of photography, make their domestic experiences in the matter of his work. 
If the autobiographical aspect could be a common feature of many artworks, everyday life as a creative pretext materializes through the photographic technique and the evolution of the phenomenon of family album. Thus, during the 80s and 90s artists that capture their own reality as an artistic project arise. Artists like Nan Goldin and Richard Billingham, which seem to reflect an absolute spontaneity, using a raw photo with flash and without artifice; others, such as Sally Mann, who turn to a more careful and precious aesthetics. These prior to the arrival of the digital age, jobs are the prelude to a type of young artists whose work can not be understood without this ocean of images representing internet, social networks and how they work as windows of the everyday. Olivia Bee, Maya Kapouski or Alejandra vacuii, perform visual diaries that ride between analog and digital, the domestic and the artistic, forming proposals related to the same visual world created and developed by domestic and private photographic practices, oversized now online.

\section{CONTENIDO}

Introducción.

La técnica fotográfica, con una rápida expansión propiciada por los avances técnicos, supuso un cambio de paradigma en el ámbito de la representación visual. Su aparente fidelidad como documento en comparación a la pintura ${ }^{1}$ u otros medios de representación, o su reproductibilidad, entre otras características, contribuyeron a la modificación de hábitos sociales, tanto en el ámbito público como privado ${ }^{2}$, además de propiciar un giro radical en las investigaciones en ciencias emergentes como la antropología, en los estudios médicos o en las técnicas de control social.

Dentro del ámbito privado, la gran expansión se produce masivamente con la llegada de Kodak y el lanzamiento de la primera cámara de rollo de papel en 1888. Toda la complejidad técnica que albergaba la toma fotográfica se simplificaba de tal manera que el usuario solo debía presionar el disparador y entregar la cámara en un lugar especializado para obtener las imágenes en papel. "Usted apriete el botón, nosotros hacemos el resto" fue el eslogan que la compañía eligió para lanzar al mercado esta nueva máquina, lema no falto de verdad. Kodak activó además importantes campañas publicitarias que contribuyeron a esta rápida expansión ${ }^{3}$.

Todos estos avances dan lugar a la fotografía doméstica y al desarrollo del álbum familiar. Este fenómeno tendrá su lectura desde el mundo del arte en el trabajo de numerosos artistas, muchos de ellos en el medio fotográfico, que trabajan sobre lo doméstico y familiar.

Con la llegada de la era digital y el desarrollo de internet y las redes sociales, se incentiva la práctica de los diarios visuales en los que artistas, generalmente muy jóvenes, muestran su visión de su entorno más inmediato utilizando como medio la fotografía, desarrollando trabajos con un marcado cariz autobiográfico, con imágenes que captan la banalidad de lo cotidiano. Nos encontramos ante verdaderas autobiografías visuales que, en ocasiones, logran una gran conexión con el público y atraen a numerosos seguidores que se interesan por la vida doméstica del artista. Olivia Bee, Maya Kapouski y Alejandra Vacuii son una pequeña muestra de estos artistas que comenzaron realizando ese tipo de diarios para, a partir de ellos, iniciar una fructífera trayectoria profesional o artística .

\section{Desarrollo.}

\section{Álbum familiar y arte.}

Aunque la difusión de la práctica de la fotografía en los ámbitos privados no puede atribuirse únicamente a Kodak (cambios sociales, antropológicos...), si hay que tener en cuenta que fue parte fundamental en la difusión de la fotografía en el entorno doméstico, no solo por el lanzamiento de una cámara accesible por su coste y fácil manejo para cualquier usuario, también por la influencia de grandes campañas publicitarias que motivaban a los usuarios a fotografiar la vida familiar en diversas situaciones como viajes, celebraciones o acontecimientos familiares. La cámara fotográfica se convierte así en un dispositivo cotidiano, imprescindible en los momentos significativos de la vida familiar, y los usuarios comienzan a coleccionar sus recuerdos en álbumes de fotografías.

El fenómeno del álbum familiar surgido a finales del siglo XIX, ha persistido hasta la actualidad, aunque su forma se ha ido modificando junto con el desarrollo tecnológico, la digitalización y los cambios en modelos sociales y hábitos sociales.

\footnotetext{
${ }^{1}$ André Bazin reflexiona sobre la importancia de la fotografía para que la pintura quedase liberada de su función de representación fiel de la realidad en el texto "Ontología de la imagen fotográfica". BAZIN, André. "Ontología de la imagen fotográfica". En: BAZIN, André, Qué es el cine. $10^{\mathrm{a}}$ de, Madrid: Rialp, 2008.

${ }^{2}$ NARANJO, Juan, et al. Fotografía, antropología y colonialismo (1845-2006). Barcelona: Gustavo Gili, SL, 2006. pp 11.

${ }^{3}$ A. MUNIR, Kamal; and PHILLIPS, Nelson. "El Nacimiento Del Momento Kodak". En: VICENTE, Pedro (ed). Álbum de Familia.

[Re]Presentación, [Re]Creación e [in]Materialidad De Las Fotografías Familiares. La Oficina, Diputación provincial de Huesca, 2013.
} 
Es evidente como la idea de álbum familiar penetra en la creación artística, tal y como sostiene Ana María Guasch, como una parte fundamental en el paradigma del archivo, que implica aquella "creación artística basada en una secuencia mecánica, en una repetitiva letanía sin fin de la reproducción" ${ }^{4}$. Lo mismo que la fotografía doméstica, ligada a él de forma inevitable, comienza también a interesar a algunos artistas como modelo de construcción de su proyecto artístico, siendo innumerables los que utilizan la temática doméstica o privada como centro de sus obras. Dentro de esta tendencia, que se desarrolla sobre todo durante la segunda mitad del siglo XX, destacan una serie de artistas cuyo trabajo se centra fundamentalmente en su propia cotidianidad. Tratan el aspecto autobiográfico desde una perspectiva en la que priman visiones de lo privado. Un ejemplo significativo de los primeros autores que trabajaron desde esos planteamientos puede ser el caso de Emmet Gowin. "Sus primeras obras recogen escenas de la vida cotidiana, donde tanto Edith, su mujer — con la que se casó en 1964, como su familia, cobran un papel protagonista. Aún así, será su esposa, desde los comienzos y hasta el final, el motivo principal más reiterado de sus obras" ${ }^{5}$.

Aunque encontramos muchos artistas que trabajan desde estas perspectivas, no es hasta los años 70 que se desarrolla propiamente un nuevo lenguaje autobiográfico en el que la realidad personal del artista se muestra sin tapujos. Son aquellos de la mal llamada "Escuela de Boston", término que engloba a una serie de artistas que tienen a "Diane Arbus y Larry Clark como precursores de una forma de enfrentarse a la realidad y de plasmar su propia vida a través de la fotografía" ${ }^{6}$. Se podrían citar muchos otros, destacando a Nan Goldin y su "Balada de la dependencia sexual", ejemplo de fotografía cruda, sin aparentes artificios. Tendencia que sería desarrollada posteriormente por otros artistas y en otros países, como puede ser la conocida obra de Richard Billingham o la del español Alberto García Álix. Hay quienes sin embargo, utilizando la misma temática, desarrollan un tipo de trabajo en el que la estética preciosista es una característica fundamental. El ejemplo más destacado sería Sally Mann, que fotografió a su propia familia durante años con un tipo de imagen aparentemente más elaborada y cuidada que la de otros artistas.

Todos estos artistas, cuya obra nace de un afán autobiográfico y una preocupación por lo doméstico, tendrán una fuerte influencia en artistas posteriores, que abordarán su trabajo creativo en una realidad social muy distinta con el desarrollo tecnológico y la llegada de la fotografía digital, la creación de nuevos dispositivos de toma de fotografías y la extensión de internet, de las redes sociales y la proliferación de plataformas y aplicaciones en las que los usuarios muestran su día a día a través de imágenes. Estas circunstancias han sido un medio propicio para que artistas jóvenes creen y muestren sus autobiografías visuales, creando un diálogo con los espectadores diferente, más allá de un contexto artístico comparativamente más cerrado.

\section{El nuevo álbum familiar. De la estantería al espacio virtual.}

"El álbum -de familia- surge de la imagen fotográfica pero participa del teatro y en general de la literatura por la existencia de un argumento y de unos protagonistas, pero sobre todo por la inclusión de la voz del narrador o el autor. Participa del arte en su visualidad y en su capacidad de erigirse como un objeto separado y autónomo para su contemplación" ${ }^{7}$. Nuria Enguita resume en su texto "Del álbum de familia al Facebook" las reflexiones de varios autores sobre el funcionamiento del álbum familiar y la importancia de la narración implícita o del narrador mismo. Un álbum que se limitaba a reflejar la vida familiar, aunque sin un carácter estrictamente privado, ya que este repositorio de la memoria familiar también se concibe para ser mostrado en un entorno cercano pero externo. Se basa en convenciones sociales, tipologías de posado y eventos que forman parte de una estereotipada construcción social de la familia y lo doméstico.

Toda esta construcción se ha visto modificada por el paso del álbum familiar al espacio virtual y el desarrollo frenético de la fotografía digital. Todos esos nuevos dispositivos que, como los teléfonos móviles o las tabletas digitales, incluyen una cámara fotográfica facilitan la generación de millones de imágenes a diario, que además son compartidas y exhibidas en las redes sociales. Imágenes que pronto caen en el olvido y pasan a formar parte de ese inconmesurable archivo que es la red. Así, la conjugación de Internet con los dispositivos de captura fotográfica al alcance de cualquiera, han modificado nuestra manera de relacionarnos con la fotografía. A pesar de que todavía se entiende como una forma de preservar la memoria de aquello que hemos vivido, la captura y difusión de imágenes a través de las redes sociales de forma tan inmediata ha generado que, como usuarios, comencemos a utilizar estas fotografías como elementos de usar y tirar. O que se comiencen a registrar masivamente no solo imágenes de los grandes eventos y acontecimientos familiares, como "bodas, bautizos y comuniones", sino que se construyen relatos de imágenes a partir del registro y difusión de "microacontecimientos" de la vida diaria más anodina o intrascendente.

\footnotetext{
${ }^{4}$ Ana María Guasch habla de dos grandes paradigmas bajo los que se suelen analizar el arte de las primeras vanguardias. Se refiere a la obra única y a la multiplicidad del propio objeto artístico. Según la autora, existe un tercer paradigma, el del archivo, bajo el cual se engloban una serie de obras con unas características relacionadas con el concepto archivístico. GUASCH, Ana M. Arte y Archivo, 19202010. Genealogías, Tipologías y Discontinuidades. Madrid: Akal, 2011.

${ }^{5}$ Disponible en <http://exposiciones.fundacionmapfre.org/gowin/es/> [consultado el 7 de mayo de 2015].

${ }^{6}$ SEGADE, Manuel. "No hubo una escuela de Boston". En: SEGADE, Manuel (de), Familiar Feelings. Sobre el grupo de Boston. Santiago de Compostela: Xunta de Galicia, Consellería de Cultura e Turismo, Centro Galego de Arte Contemporáneo, 2009. pp. 12.

${ }^{7}$ ENGUITA, Nuria. "Del álbum de familia al facebook". En: ESTÉVEZ GONZÁLEZ, Fernando; y DE SANTA ANA, Mariano (eds). Memorias y Olvidos Del Archivo., Santa Cruz de Tenerife etc.: Lampreave, 2010.
} 
Dentro de esta cultura de lo inmediato, existen diferentes aplicaciones que contribuyen a este consumo fotográfico masivo en el que cualquier usuario, ya sean profesionales de la imagen, celebridades o usuarios anónimos, muestra un pedazo de su cotidianidad a través de imágenes. Édgar Gómez en su libro "De la cultura Kodak a la imagen en red. Una etnografía sobre fotografía digital”, realiza un análisis de muchas de estas aplicaciones y plataformas, ofreciendo además una perspectiva general sobre algunos de los estudios teóricos que se están llevando a cabo en estos ámbitos, consiguiendo "reflexionar sobre las profundas transformaciones en la práctica fotográfica a partir del uso de la tecnología digital". ${ }^{8}$

Teniendo en cuenta la celeridad de las redes, Édgar Gómez menciona a Flickr como una de las mayores y activas redes de consumo de fotografías, pero en estos momentos podemos hablar de otras muchas que, en un espacio en continua transformación, han surgido desde la publicación de su libro. Algunas de las más destacadas son Instagram, Pinterest, Tumblr o incluso el gigante Facebook, a través del cual numerosos usuarios crean páginas sobre diversas temáticas centradas en la imagen fotográfica. En este contexto hay que mencionar además herramientas para la creación de blogs como Wordpress o Blogger, o plataformas más enfocadas a profesionales de la imagen como Behance.

En el presente texto se pretenden ofrecer tres ejemplos significativos para contextualizar a los artistas que, partiendo de la fotografía autobiográfica desde lo doméstico, utilizan los medios citados para generar una narración subjetiva de sus vivencias. El uso de estas aplicaciones por parte de estos jóvenes artistas, unido a las temáticas cotidianas, cercanas, para crear diarios fotográficos o visuales autobiográficos, ha generado un acercamiento de este tipo de creadores a un numeroso público que consume y comparte esos momentos privados reconvertidos en material artístico.

La gran diferencia entre este tipo de autores y los demás usuarios que comparten sus vivencias en las redes, radica en la intencionalidad artística y la elaboración de un discurso estético diferenciado. Generan estos diarios visuales para convertir en objeto artístico su propia cotidianidad, incluso banalidad, como hicieron en el circuito artístico los antecesores antes citados .

Aunque existen numerosos ejemplos que ilustrarían estas premisas, se han seleccionado una muestra de artistas presentes en el circuito artístico o en el mundo de la fotografía profesional, estando sus proyectos autobiográficos en sus comienzos. Hay que destacar que son artistas que han convivido con la transición de la fotografía analógica a la digital, por lo que es habitual que haya una combinación de ambas técnicas en su trabajo.

Olivia Bee, (Oregon, EEUU, 1994), se inicia precozmente en la fotografía a los 11 años, y empieza a ser conocida en el mundo de la fotografía por los retratos de su mundo adolescente que difunde por las redes, desde una perspectiva inocente y fresca y con una estética entre lo espontáneo y la ensoñación.

La fotografía analógica y las nuevas tecnologías dialogan para generar el pequeño pero intenso universo de Bee. Un paseo por su página web o cualquiera de sus perfiles en redes sociales te introduce en un mundo en el que se mezclan estas fotografías autobiográficas, directas y sin filtros, con otras conceptualmente más elaboradas. Fotografías que son una muestra del mundo adolescente en primera persona, las primeras experiencias, las amistades, el sexo.

La estética espontánea y la aparente honestidad de sus imágenes fueron un punto de partida para que sus diarios visuales tuviesen una gran popularidad a través de las redes. La vida y andanzas de la adolescente Olivia Bee se convertía en objeto de atención y seguimiento para numerosos usuarios.

Esta visibilidad, unida a su marcado estilo estético, se convierte en trampolín para ser captada por grandes marcas y convertirse en una joven promesa de la fotografía comercial. En la actualidad ya ha fotografiado y dirigido campañas para Cacharel, Adidas o Hermés, entre muchas otras.

Hay que destacar que el interés por Olivia Bee no proviene únicamente de esa vertiente profeisonal y comercial, las fotografías de su mundo privado interesan en el ámbito artístico, habiendo expuesto su trabajo en Nueva York, Madrid o París, y siendo publicado en revistas como EXIT (Exit autobiografía). Una artista que, con tan solo 21 años, ha conseguido conquistar ámbitos con un difícil acceso a edades tan tempranas. Éxito que probablemente no habría sido posible sin los medios de difusión y visibilidad que ofrece internet.

\footnotetext{
${ }^{8}$ GÓMEZ, Edgar. De la cultura Kodak a la imagen en red. Una etnografía sobre fotografía digital. Barcelona: Editorial UOC, 2012. pp 27.
} 


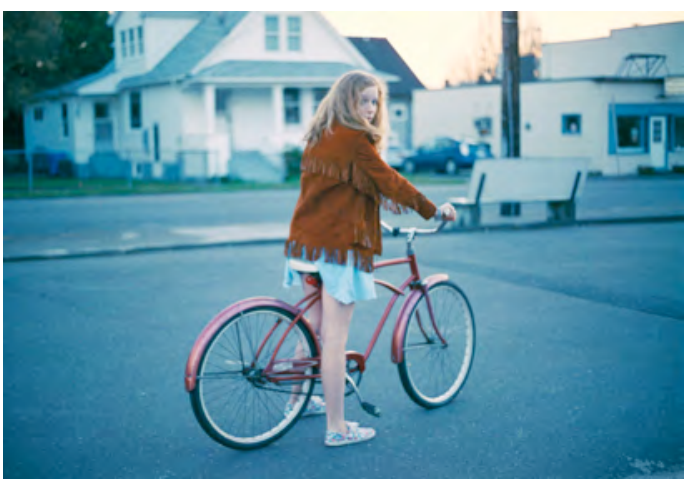

Olivia Bee

Maya Kapouski (A Coruña, 1987) es una artista que aborda la mayoría de sus trabajos desde la fotografía, aunque muchas de sus obras tienen un carácter multidisciplinar. Sus diarios visuales son un reflejo de sus intereses artísticos y una parte fundamental de su trabajo que influye en sus otras facetas profesionales y artísticas.

Al igual que Olivia Bee, Maya realiza fotografías de su propia cotidianidad, pero como una faceta paralela y experimental dentro de su trabajo artístico: "no hay ninguna intención de lucirse, es solo un archivo, un diario puro y duro que hago para mi, a través del que he intentado aprender a mirar y fotografiar. Lo bueno de hacerlo para mi es que me permito equivocarme y experimentar" ${ }^{9}$.

Su propia concepción del diario hace que a través de éste aborde la tarea autobiográfica sin tapujos y sin imposiciones conceptuales o estéticas. En muchas de sus fotografías se puede observar una sublimación de lo ordinario, inmortalizando lo que carecería de importancia por ser demasiado común.

Sus viajes, su mundo doméstico y sus intereses artísticos se ven reflejados en la elaboración de sus diarios. Maya plasma en sus imágenes la fascinación por lo banal, las reticencias a vivir como un adulto y su particular visión del mundo que le rodea. Todo este universo personal funciona como hilo conductor para comprender una trayectoria que se mueve entre el arte y la fotografía profesional, fundamentalmente de moda, en la que influye inevitablemente el estilo espontáneo y doméstico de sus diarios.

Su formación artística y su recorrido profesional en diferentes ámbitos creativos hace que el trabajo de Maya Kapouski sea técnicamente versátil. Fotografía analógica y digital se combinan en sus redes sociales, técnicas con las que consigue diferentes resultados estéticos con los que plasma las diversas facetas que ofrece.

Su actividad en las redes sociales ha contribuido a obtener una mayor visibilidad. Con numerosos seguidores, es una fotógrafa consagrada que compagina su trayectoria en la fotografía profesional con una interesante carrera artística, exponiendo en numerosas galerías, sin abandonar ese espacio de experimentación en el que ha convertido sus diarios.

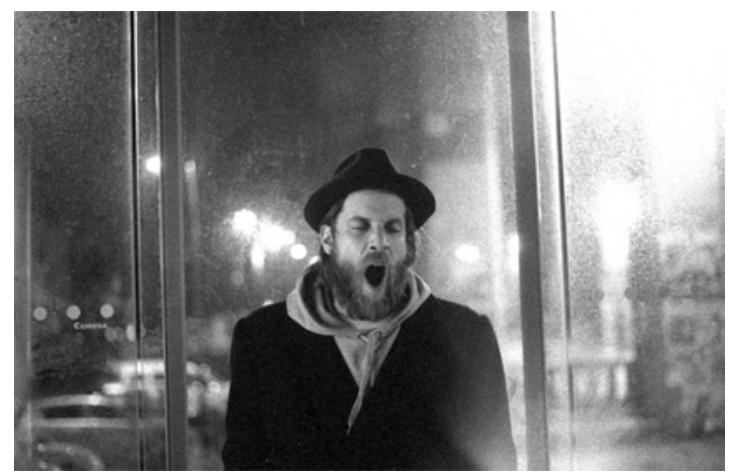

Maya Kapouski

\footnotetext{
${ }^{9}$ Disponible en:<http://tener-cultura.blogspot.com.es/2015/01/maya-kapouski.html>. [consultado el 7 de mayo de 2015].
} 
Alejandra Vacuii (Ourense, 1987) sería un caso menos relevante si sólo atendemos a su proyección en el mundo del arte. Sin embargo, es un ejemplo muy significativo dentro de estos diarios fotográficos expuestos en las redes virtuales. Desde hace años, Alejandra cuenta con numerosos blogs, perfiles en plataformas y webs, que han ido evolucionando en consonancia con su estilo y su maduración creativa. Cuenta con seguidores fieles que se convierten en observadores de sus vivencias, que ella muestra de forma intencionadamente sesgada.

Estéticamente, Alejandra trabaja desde un estilo mucho más preciosista y elaborado, que le otorga un aura de ficción que no poseen los trabajos de Olivia o Maya. En sus diarios podemos ver fotografías con una estética casi cinematográfica, más sumida en la oscuridad y que proyecta sentimientos melancólicos. Destaca el uso del blanco y negro en una narración autobiográfica discontinua, que enfatiza la relación entre realidad y ficción.

Fotógrafa de formación, Alejandra se dedica a la fotografía profesional en ámbitos como la moda y la fotografía social, donde su marcado estilo estético también se ve reflejado. En sus diarios se pueden observar imágenes asociadas a su trabajo como profesional, pero casi siempre son referencias a momentos de tránsito, de descanso. De esta manera se genera un diálogo entre la vida personal y la profesional. La artista muestra pequeños momentos escogidos para acabar generando estas realidades ficcionadas, numerosas y mostradas en diferentes redes, que de alguna forma complementan su autobiografía contada en imágenes. Espacios de ensoñación donde los juegos de luces y las composiciones muy cuidadas son protagonistas.

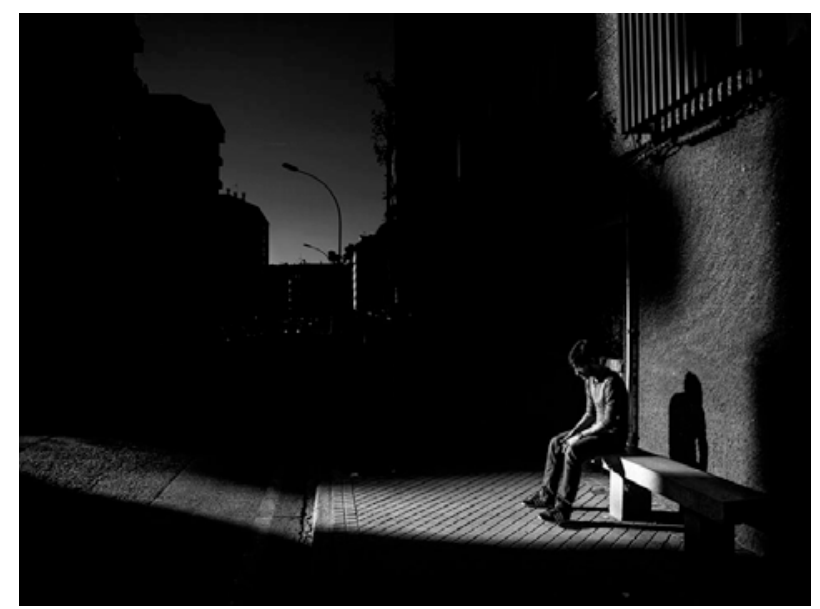

Alejandra Vacuii.

\section{Conclusiones.}

En el ámbito familiar, la fotografía contribuye a conservar los recuerdos de forma privada, y mostrarlos de forma pública. Actualmente, las redes sociales se han convertido en álbumes virtuales repletos de fotografías domésticas que son más públicos que nunca, ya que se ponen a disposición de un gran número de usuarios. Se han modificado los usos del álbum, antes reducido a un público concreto y escogido, para formar parte del inabarcable océano de imágenes que circulan a través de internet.

En este nuevo escenario, artistas como Olivia Bee, Maya Kapouski o Alejandra Vacuii, muestran su cotidianidad a través de diarios visuales, construyendo autobiografías que son parte fundamental de la trayectoria como creadoras, ya sea por haber sido un trampolín para acceder al mundo artístico o profesional, como por suponer un vínculo de unión entre otras facetas.

Vidas sesgadas que suscitan interés entre el vasto público de las redes sociales y que provocan un acercamiento del arte a un espectador no especializado. Fotografías de lo común, de las vivencias domésticas de artistas con proyecciones distintas y estilos muy diferenciados. Universos visuales en forma de diarios, nuevos lenguajes para jóvenes artistas que parecen recoger y llevar a otros espacios el testigo de aquellos que revolucionaron la fotografía doméstica dentro del arte. 


\section{FUENTES REFERENCIALES.}

A. MUNIR, Kamal; and PHILLIPS, Nelson. "El Nacimiento Del Momento Kodak". En: VICENTE, Pedro (ed). Álbum de Familia. [Re]Presentación, [Re]Creación e [in]Materialidad De Las Fotografías Familiares. La Oficina, Diputación provincial de Huesca, 2013.

BAZIN, André. “Ontología de la imagen fotográfica”. En: BAZIN, André, Qué es el cine. 10å de, Madrid: Rialp, 2008.

CASTELLANOS, Paloma. Diccionario Histórico De La Fotografía. Madrid: Ediciones Istmo, S.A, 1999.

ENGUITA, Nuria. "Del álbum de familia al facebook". ESTÉVEZ GONZÁLEZ, Fernando; y DE SANTA ANA, Mariano (eds), Memorias y Olvidos Del Archivo. Santa Cruz de Tenerife etc.: Lampreave, 2010..

FREUND, Gisèle. La Fotografía Como Documento Social. 1ạ ed. Barcelona: Gustavo Gili S.A, 2004.

GÓMEZ, Edgar. De la cultura Kodak a la imagen en red. Una etnografía sobre fotografía digital. Barcelona: Editorial UOC, 2012.

GUASCH, Ana M. Arte y Archivo, 1920-2010. Genealogías, Tipologías y Discontinuidades. Madrid: Akal, 2011.

NARANJO, Juan, (ed). Fotografía, antropología y colonialismo (1845-2006). Barcelona: Gustavo Gili, SL, 2006.

SEGADE, Manuel. "No hubo una escuela de Boston". En: SEGADE, Manuel (ed), Familiar Feelings. Sobre el grupo de Boston. Santiago de Compostela: Xunta de Galicia, Consellería de Cultura e Turismo, Centro Galego de Arte Contemporáneo, 2009.

VICENTE, Pedro, (ed). Álbum De Familia. [Re]Presentación, [Re]Creación e [in]Materialidad De Las Fotografías Familiares. Diputación Provincial de Huesca, La Oficina ed. Madrid: La Oficina de Arte y Ediciones S.L, 2013.

VV.AA. EXIT\#49 Autobiografía. 2013, Vol 49.

Referencias web.

Bee, Olivia. <http://oliviabee.com> [consultado el 9 de mayo de 2015].

Gowin, Emmett. <http://exposiciones.fundacionmapfre.org/gowin/es/> [consultado el 7 de mayo de 2015].

Kapouski, Maya. <http://www.mayakapouski.com> [consultado el 9 de mayo de 2015].

<http://tener-cultura.blogspot.com.es/2015/01/maya-kapouski.html> . [consultado el 8 de mayo de 2015].

Vacuii, Alejandra <http://alejandravacuiidiary.tumblr.com> [consultado el 9 de mayo de 2015].

<http://cosasquenovolveranasuceder.tumblr.com> [consultado el 9 de mayo de 2015]. 